\title{
A hybrid model of QFD, SERVQUAL and KANO to increase bank's capabilities
}

\author{
Mohsen Kashi $^{\mathrm{a}^{*}}$, Mohammad Ali Astanbous ${ }^{\mathrm{a}}$, Mojtaba Javidnia ${ }^{\mathrm{b}}$ and Hasan Rajabi ${ }^{\mathrm{a}}$
}

${ }^{a}$ Department of Management, Islamic Azad University, Semnan Branch, Semnan, Iran

${ }^{b}$ Department of Management, Young Researchers Club, Semnan Branch, Islamic Azad University, Semnan, Iran

\begin{tabular}{l}
\hline A R T I C L E I N F O \\
\hline Article history: \\
Received March 29, 2012 \\
Accepted 18 June 2012 \\
Available online \\
June 19 2012 \\
\hline Keywords: \\
SERVQUAL \\
Kano \\
QFD \\
Banking system
\end{tabular}
\begin{abstract}
A B S T R A C T
In global market, factors such as precedence of competitors extending shave on market, promoting quality of services and identifying customers' needs are important. This paper attempts to identify strategic services in one of the biggest governmental banks in Iran called Melli bank for getting competition merit using Kano and SERVQUAL compound models and to extend operation quality and to provide suitable strategies. The primary question of this paper is on how to introduce high quality services in this bank. The proposed model of this paper uses a hybrid of three quality-based methods including SERVQUAL, QFD and Kano models. Statistical society in this article is all clients and customers of Melli bank who use this banks' services and based on random sampling method, 170 customers were selected. The study was held in one of provinces located in west part of Iran called Semnan. Research findings show that Melli banks' customers are dissatisfied from the quality of services and to solve this problem the bank should do some restructuring to place some special characteristics to reach better operation at the heed of its affairs. The characteristics include, in terms of their priorities, possibility of transferring money by sale terminal, possibility of creating wireless pos, accelerating in doing bank works, getting special merits to customers who use electronic services, eliminating such bank commission, solving problems in least time as disconnecting system, possibility of receiving foreign exchange by ATM and suitable parking in city.
\end{abstract}

(C) 2012 Growing Science Ltd. All rights reserved.

\section{Introduction}

During the past few decades, global economy has changed from goods toward service and is regarded as the most important long-term tendencies in today's economy (Ueltschy et al., 2007); so that, according to statistics, nearly $70 \%$ of workforce is working at service sector (Mirghafori \& Maki, 2007). Although service business grows rapidly in developing countries, several countries pay less attention to quality of offering services. In fact, many service businesses have monopolized the market and do not care about service quality (Yanggui et al., 2003). Offering high quality service is regarded as one of the most important elements, which results in customer satisfaction and only those companies and institutes may permanently offer high quality service that have comprehensive approach in relation to customer and have deep commitment toward their customers (Hapson, 2002).

* Corresponding author. Tel: +989125310359

E-mail addresses: mhsnkashi.mi@gmail.com (M. Kashi) 
Any implementation of service quality has several advantages including: 1) quality of service results in customer satisfaction, increasing loyalty and market share 2) quality of service is regarded as fundamental element of customer marketing. Satisfied and loyal customer is regarded as gratuitous advertisement resource; on the other hand, dissatisfied customer has opposite behavior and narrates his negative experiences for other potential customers. Researches indicate that having $1 \%$ decrease in customer satisfaction is equivalent to $5 \%$ decrease in capital return. There are also other evidences to believe that cost of attracting one new customer is 5 times higher than customer retention (Richheld \& Sasser 1990). Therefore, obtaining competitive advantage through service quality requires recognition of quality of service with respect to customers (Wang \& Soha 2000).

There are literally various methods for assessing service quality and SERVQUAL has been considered as one of the most important one (Parasuraman et al., 1985). According to SERVQUAL model, customers evaluate quality of service through 5 aspects including tangibles, reliability, responsibility, assurance, empathy. Quality of a service is a result of comparing customer expectations with their perceptions from offered service (Ramseook- munhuurrun, 2010). Some people criticized Parasuraman's model for hospital application and divided quality determinants in 2 classes including: tangibles and non-tangibles (Zaim et al., 2010). The fact that quality of perceived product is gradually changing into the most important factor for competition all over the world has changed the name of present age as the age of quality (Peeler, 1997). Quality assessment has had a long history and it originates back to early 70's (Akbaba, 2006). Despite the fact that many researchers studied the definition of service in the past, however, offering exact definition of service is a difficult task. Sophisticated term with various meanings and may cover broad range of personal service as a product and people normally specify this term by pointing to its properties (Gronroos, 2000).

The term of quality has different aspects and learning the concept of quality of service without recognizing its aspects is not possible (Groonros, 2000). Quality of service is normally determined as demand for quality of service offered by organization and performance of service, which is expected by employees. Groonros (2000) considered three aspects of service including, which includes technical quality of product, duty quality and mental image. Measuring the quality of a service is difficult task since it is non-tangible, heterogeneous and non-separable (Meng et al, 2009: 77) and these aspects are summarized in Table 1.

\section{Table 1}

Properties of service

\begin{tabular}{ll}
\hline Property of Service & Result \\
\hline Non-Tangible & It is not possible either to save service or to register service as patent. \\
Heterogeneous & $\begin{array}{l}\text { Offering service, which absorbs customer satisfaction, is based on activities of employees and the } \\
\text { quality of service is a function of some non-controllable factors. }\end{array}$ \\
$\begin{array}{l}\text { Simultaneous production and } \\
\text { consumption }\end{array}$ & $\begin{array}{l}\text { Customers may take part in and/or influence on exchange, customers may affect each other or on the } \\
\text { result of a service, lack of concentration is necessary, mass-production is a great problem. }\end{array}$ \\
Non-corruption & Simultaneous supply and demand of service is not possible, it is impractical to refund or resale service \\
\hline
\end{tabular}

Lehtinen and Lehtinen (1991) offered comprehensive analysis of quality of service, which refers to quality of service as a 3-D approach and it consists of physical quality, exchange and aspects of organizational quality. According to 2-D approach, quality of service consists of quality of process and quality of consequence. Quality of process is the assessment of customer partnership in process of offering service and quality of assessing consequences of service. Some people insist on performance on modeling perception of quality of service. According to most common definition, quality of service consists of customer perceptions associated with received service (Carman 1990).

In fact, it is possible to say that perception of quality of service depends on offering the service to customers. Parasuraman et al. (1985) presented a model for quality of service with 10 components. Parasuraman (1991) further offered 5 aspects of quality of service, which has been widely used in 
most organizations through psychometrics and studying common properties of quality of service (Warden 2003). Table 1 indicates 5 aspects of SERVQUAL and courtesy.

\section{Table 2}

Five aspects of SERVQUAL and courtesy

Having suitable equipments and neat employees

Reliability Offering correct, suitable service and fulfilling obligations

Responsibility

Preference of employees for assistance to customers and offering prompt service

Assurance Knowledge and skill of employees for creating assurance

Empathy

Attention of customers and having special behavior with each customer

Courtesy Polite and respectful behavior of employees

In fact, Parasuraman et al. (1985) and Dagger (2007) presented conceptual framework of quality of service through the concept of gap at quality of service within model called gap analysis. Gap analysis model shows an exchange between activities of organization and a link between these activities and customer satisfaction from a particular service.

\section{The proposed model}

The proposed model of this paper uses a hybrid of three well-known quality methods including SERVQUAL, QFD and Kano models. Fig. 1 shows details of the proposed model of this study. Inclination for providing high quality service plays important role in service industries such as banks, insurance, etc. since service quality is very important for survival and profitability. Today customer satisfaction and service quality play important role for most service industries. Quality is not a one dimensional phenomenon and achieving to service or production quality without recognizing quality important aspect is impossible.

Customer satisfaction is a personal evaluation influenced by subjective prospects, some people introduced satisfaction, and dissatisfaction based on endorsement or intolerance of customer personal prospects about received commodity and services. In governmental part, customer satisfaction includes customers' relationships, their reaction and past experiences by received service. In this article, we distributed 4 questionnaires among customers of a governmental banks called Melli bank. These questionnaires include SERVQUAL, Kano and two questionnaires related to quality operation development. For evaluating services quality we use SERVQUAL model extended by Parasuraman (1991) to determine service quality using distance organization services quality operation. Therefore, service quality includes imagined and interdicted as customer judgeship about total received position and services' skill. Expected quality deals with description expectation about received services. In this scale known as distance analyze, services quality has been defined as measuring rate of meeting customer expectation from provided services quality. The proposed SERVQUAL investigation of this article includes 27 questions distributed among Melli bank customers and the results show dissatisfaction of customers by quality services. As except two traits, often there is a negative gap (dissatisfaction) in service quality traits and for gaining gap, the following relationship is used.

Gap $=$ operational average -expectation average,

where operational average is associated with the existing norms of customers' expectation while average expectation is associated with what customers normally expect from a bank. The gap created from operational average and expectation average shows Melli bank customers' satisfaction or dissatisfaction, which is either positive or negative. If the resulted gap becomes negative, it shows that customers' expectations are beyond Melli bank service and this means customers dissatisfaction. Table 3 shows the gap extracted from our survey. As Table 3 shows, except dimensions 16 and 19, all other dimensions are in weak positions and negative sign shows customers dissatisfaction from existed service. Obviously, if the gap were positive, it would show customer satisfaction from existent services. 




Fig 1. Conceptual model

\section{The results}

There are many criticisms about SERVQUAL model, for instance, many believe that SERVQUAL is only for measuring customers' satisfaction from provided services by firm and it is not suitable method for measuring satisfaction from productions. 
Table 3

Traits of services quality based on SERVQUAL model

\begin{tabular}{|c|c|c|c|c|c|}
\hline No. & Traits of service quality & $\begin{array}{c}\text { Average } \\
\text { performance }\end{array}$ & $\begin{array}{c}\text { Average } \\
\text { expectations }\end{array}$ & Gaps & $\begin{array}{l}\text { Service } \\
\text { quality }\end{array}$ \\
\hline 1 & Using modern and update equipment in bank branches & 5.00 & 7.00 & -2.00 & Weak \\
\hline 2 & Regular and ordered arrangement of branches (purity and clarity) & 2.23 & 7.76 & -2.53 & Weak \\
\hline 3 & Purity and uniformity of employees of bank & 5.30 & 9.09 & -2.79 & Weak \\
\hline 4 & Bank equipment quality for usage of customers from & 6.49 & 7.43 & -0.94 & Weak \\
\hline 5 & Suitable space for accommodating waiting customers & 4.31 & 7.88 & -3.57 & Weak \\
\hline 6 & Eliminating some bank wage & 3.98 & 8.04 & -4.06 & Weak \\
\hline 7 & Providing fast service & 4.35 & 7.29 & -2.94 & Weak \\
\hline 8 & Providing useful information during the banking operations & 6.80 & 6.84 & -0.04 & Weak \\
\hline 9 & Resolving any conflict in minimum amount of time & 2.84 & 5.37 & -2.54 & Weak \\
\hline 10 & Possibility of having wireless pos & 4.70 & 6.88 & -2.18 & Weak \\
\hline 11 & Possibility of transferring money by pos & 4.80 & 6.8 & -2.00 & Weak \\
\hline 12 & Granting special priority for customers who use electronic services & 5.20 & 5.50 & -0.30 & Weak \\
\hline 13 & Employee welcome and openness attitudes & 4.58 & 6.70 & -2.12 & Weak \\
\hline 14 & Rate of customers' trust to their expectations & 6.76 & 6.85 & -0.09 & Weak \\
\hline 15 & Rate of satisfaction to "Customer always has the right" & 5.31 & 5.68 & -0.37 & Weak \\
\hline 16 & Using specialist staff in their job position & 6.80 & 6.70 & +0.1 & Strong \\
\hline 17 & Guiding customers by special officer before shifting the system & 4.80 & 6.41 & -1.61 & Weak \\
\hline 18 & TV for providing necessary information & 4.77 & 6.98 & -2.21 & Weak \\
\hline 19 & Suitable number of branches and their dispersal in city & 7.27 & 6.05 & +1.22 & Strong \\
\hline 20 & Suitable branch working hours & 6.40 & 6.80 & -0.40 & Weak \\
\hline 21 & Suitable number of pos in different organizations & 6.84 & 6.98 & -0.14 & Weak \\
\hline 22 & Suitable and standard parking facilities & 1.67 & 6.21 & -4.54 & Weak \\
\hline 23 & Possibility of receiving foreign exchange by ATMs & 1.70 & 6.52 & -4.82 & Weak \\
\hline 24 & Rate of operator accountability to staff's duties & 4.96 & 7.00 & -2.04 & Weak \\
\hline 25 & High speed and accurate payment system & 5.14 & 8.51 & -4.26 & Weak \\
\hline 26 & The amount of information customers have on electronic transaction costs & 2.96 & 7.21 & -4.26 & Weak \\
\hline 27 & Staff support to answer questions and concerns & 2.58 & 6.70 & -2.12 & Weak \\
\hline
\end{tabular}

There are some basic elements of Kano model (Kano et al., 1984) for product development and customer satisfaction and Kano model classifies customer preferences into five categories including attractive, one-dimensional, must-be, indifferent and reverse. In Kano mode, attractive quality means are associated with objectives, which have been completely achieved and these are attributes, which are normally expected. One-dimensional quality characteristics are associated with those quality characteristics, which satisfy customers when they are fulfilled and customers are dissatisfied when they are not fulfilled. Must-be quality characteristics are associated with those attributes taken for granted when fulfilled but result in dissatisfaction when not fulfilled.

A descriptive example of this item is a bottle of juice that leaks. Customers are dissatisfied when the bottle leaks, but when it does not leak the result does not increase customer satisfaction. This is because customers expect such attributes and considers them as basic and it is unlikely that they tell the company about them when asked about quality attributes. Indifferent quality is the next component of Kano model, which refers to different aspects, which are neither good nor bad and have nothing to do with customer dissatisfaction. Finally, reverse quality is the last attributes, which is associated with a high degree of achievement resulting in dissatisfaction. For example, some people prefer to wear green shows and they are satisfied with this color but the other are not interested in such color and they prefer color red to green. In our survey, we have used the same 27 questions as we used in SERVQUAL method. The attractive traits include:

1. Eliminating some bank wages

2. Speed up in doing bank affairs

3. Solving problems in least possible time when disconnecting system

4. Possibility of creating wireless pus
5. Possibility of transferring money by pus

6. Granting special prominence to customer who use electronic services

7. Suitable parking in city

8. Possibility of receiving foreign exchanges by ATM

After determining attractive traits in the next stage, we must priorities attractive traits using quality function development (QFD). QFD is a method, which apply customer's needs in all stages of production such as designing, developing, planning and producing and it was first introduced in Japan's Mitsubishi heavy industries in 1972 (Akao, 1966). In despite of its short history, interest to 
QFD and its applications were growing in the world. Primary introduction of QFD when occurred that a question had been introduced in Akao's mind that in quality discussion we pay much attention to some sectors of process or production and there are some attempts to understand whether they have quality. Why do we have to place these important notes and points called guaranty points as control points in primary planning of our process and production? Output result of planning process with the help of quality operation development is very important to customers' needs and these causes to sever depression of technical changes. In this survey, we first ask regular Melli bank's customers to answer the questions of a questionnaire we designed (questionnaire \#3) and there are eight attractive traits to evaluate customers' needs. Next, we introduced another competitor bank called Mellat bank to the same customers and asked them about eight traits in another designed questionnaire (questionnaire \#4). We evaluated competitor organization situation, and after this stage, we evaluated operational average result of SERVQUAL about these eight traits to evaluate Melli bank function about these eight traits. Situation of competitor organization and Melli bank function in SERVQUAL model are provided in Table 4. In the next stage, we must recognize improving rates, which is the result of dividing competitor firm situation on organization situation. It means that when the outcome of this division is less than one, it shows that organization has more quality services than competitor organization and if the outcome is greater than one, it shows that competitor organization in services quality has better position than organization. For each customer's needs, move over its importance rate that state by customers, weight of each trait must be calculated using the following,

Absolute weight of each want of customer $=$ Importance rate $\times$ Improvement rate.

For prioritizing each eight attractive traits, it is sufficient that relative and absolute weight of each desired customer's needs are calculated as follows,

Relative weight of each want of customer $=($ Absolute weight + sum of absolute weight $) \times 100$

First priority: Possibility of transferring many by pos with absolute weight of 15.52

Second priority: Possibility of creation wireless pos with absolute weight of 73.46

Third priority: Speed up in doing bank affairs with absolute weight of 13.37

Fourth priority: Granting special prominence to customers who use electronic services with absolute weight of 13.03

Fifth Priority: Eliminating some bank wages with absolute weight of 11.5

Sixth priority: Solving problems in least possible time when disconnecting system with absolute weight of 11.35

Seventh priority: Possibility of receiving foreign exchanges by ATM with absolute weight of 10.99

Eighth priority: Suitable parking in city with absolute weight of 10.51

Next, we prioritized customer needs with consulting scholars and elites of banking industry, we defined 7 technical trait for Melli bank. These traits recognize the relationships on customer's wants with technical necessities in quality home. These traits include,

1. Up to dating and extending electronic banking system for providing Internet services,

2. Staff proficiency education,

3. Telling system,
4. Employment sufficient staff,

5. Recognizing problems and meeting customers' needs,

6. Preparing informational manual,

7. Developing hard ware of bank equipment.

In Table 4, relations of technical traits with each of quality traits have been interpolated where strong relationship is shown with 9, average relationship is denoted with 3 and weak relationship is shown with 1 . Therefore, process similar to what has been done about customers' necessities and wants, done with technical traits. Next, we get absolute weight of technical trait and absolute weight rate of technical trait by following relations,

Absolute weight of each technical trait $=$ absolute weight of each customer want $\times$ relation among customer want and technical trait) 
Relative weight of each technical trait $=$ (absolute weight of each technical trait $\div$ sum of absolute weight of technical trait) $\times 100$

Then we priorities technical trait:

First priority: Up to dating and extending electronic banking system for providing Internet services with absolute weight of 24.12

Second priority: Developing hardware of bank equipment with absolute weight of 21.4

Third priority: Recognizing problems and meeting customers' needs with absolute weight of 14.23

Fourth priority: Tell ring system with absolute weight of 12.30

Fifth priority: Employment sufficient staff with absolute weight of 11.77

Sixth priority: Staff proficiency education

Seventh priority: Preparing informational and guiding manual and books with the absolute weight of 7.90

As observed from the results of Table 4, up to dating and extending electronic banking system for providing internet services has first priority from technical traits. Therefore, Melli bank must solve problems to survive in competitor world.

Table 4

All priorities and their relation with customers wants have been specified

\begin{tabular}{|c|c|c|c|c|c|c|c|c|c|c|c|c|c|}
\hline Customer needs (customer wants). &  &  &  &  &  &  &  & 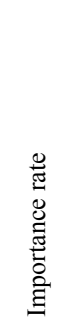 &  &  &  &  & 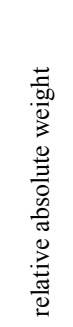 \\
\hline Eliminating some bank wages & & & & & 3 & 1 & & 8.19 & 3.65 & 3.98 & 0.91 & 7.45 & 11.5 \\
\hline Speedup in doing bank affairs by staff & 9 & 3 & 9 & 9 & 9 & 3 & 3 & 7.84 & 4.85 & 4.35 & 1.11 & 8.70 & 13.37 \\
\hline Solving problems in least possible time & 9 & 9 & & 9 & 9 & 1 & 3 & 7.54 & 2.78 & 2.84 & 0.98 & 7.39 & 11.35 \\
\hline possibility creating wireless pos & 3 & 1 & & & 3 & 3 & 9 & 7.24 & 5.69 & 4.70 & 1.21 & 8.76 & 13.46 \\
\hline $\begin{array}{l}\text { possibility transferring money by sale } \\
\text { terminal }\end{array}$ & 9 & & & & 3 & 3 & 3 & 7.47 & 6.65 & 4.80 & 1.38 & 10.3 & 15.82 \\
\hline Granting special prominence to customers & 3 & & 9 & & 3 & 3 & & 7.78 & 5.7 & 5.2 & 1.09 & 8.48 & 13.03 \\
\hline Standard and suitable parking's & 1 & & & & 9 & & 9 & 7.28 & 1.57 & 1.67 & 0.94 & 6.84 & 10.51 \\
\hline $\begin{array}{l}\text { possibility receiving foreign exchanges by } \\
\text { pos }\end{array}$ & 9 & & & & 1 & 1 & 9 & 6.81 & 1.80 & 1.70 & 1.05 & 7.15 & 10.99 \\
\hline Technical prominence of Melli bank & 70 & 70 & 50 & 70 & 40 & 70 & 70 & & & & & & \\
\hline Technical prominence of competitor bank & 80 & 70 & 50 & 60 & 40 & 70 & 80 & & & & & & \\
\hline Technical importance & 100 & 90 & 90 & 100 & 80 & 90 & 100 & & & & & & \\
\hline Absolute weight of technical trait & 360.4 & 101.4 & 154.6 & 144.8 & 31804 & 130.7 & 283.9 & & & & & & \\
\hline Relational weight of technical trait & 24.12 & 6.78 & 10.34 & 9.69 & 21.31 & 8.75 & 18.99 & & & & & & \\
\hline
\end{tabular}

In summary, we can specify all important traits based on their relative importance as traits of speed up in doing bank affairs, solving problems in least possible time when disconnecting system, possibility transferring money by pos, possibility receiving foreign exchange by pos and has mean relation (2) with possibility creating wireless pos, granting special prominence to customers who use electronic services and has weak relation (1) with suitable parking in city, which show that this trait place in first priority truly.

Second priority about technical traits, extending hard ware of bank equipment with absolute weight of 21.4 that Melli bank as a progenitor bank in providing bank new services must extend hard ware to continue its activity in competitive situation. This trait has strong relation with possibility of creating wireless pos, suitable parking in city, possibility receiving foreign exchange by ATM, also has mean relationships with speed up in doing bank affairs, solving problems in least possible time when disconnecting system. Therefore, the possibility of transferring money by pos is the second priority of 
technical necessities. Third priority is associated with recognizing problems and meeting customers' needs. Today, customers seek higher welfare and comfort. Therefore, this trait has strange relationships with speed up in doing bank affairs, solving problems in least possible time when disconnecting system, suitable parking in city and has mean relation with eliminating some bank's wages, granting special prominence to customers who use electronic services, possibility of creating wireless pos, possibility of transferring money by pos and finally has weak relationships with possibility of receiving foreign exchange by ATM. Table 4 shows details of our results.

\section{Conclusion}

This paper presented a method to identify strategic services in one of the biggest governmental banks in Iran called Melli bank for getting competition merit using Kano and SERVQUAL compound models and extending operation quality and providing suitable strategies. The study was held in one of provinces located in west part of Iran called Semnan. Research findings show that Melli banks' customers are dissatisfied from the quality of services and to solve this problem the bank should do some restructuring to place some special characteristics to reach better operation at the heed of its affairs. The characteristics include, in terms of their priorities, possibility of transferring money by sale terminal, possibility of creating wireless pos, accelerating in doing bank works, getting special merits to customers who use electronic services, eliminating such bank commission, solving problems in least time as disconnecting system, possibility of receiving foreign exchange by ATM and suitable parking in city.

\section{References}

Akbaba, A. (2006). Measuring service quality in the hotel industry: A study in a business hotel in Turkey. International Journal of Hospitality Management, 25, 170-192.

Akao, Y. (1966). Development history of quality function deployment. The customer driven approach to quality planning and deployment. Minato, Tokyo 107 Japan: Asian Productivity Organization, 339.

Carman, J. M. (1990). Consumer perceptions of service quality: An assessment of the SERVQUAL dimensions. Journal of Retailing, 66, 33-55.

Dagger, T. S., Sweeney, J.C., \& Johnson, L. W. (2007). Service quality attribute weights: How do novice and longer-term customers construct service quality perceptions? Journal of Service Research, Journal of Service Research, 10(1), 22-42.

Ekinci, Y. (2002). A review of theoretical debates on the measurement of service quality: Implications for hospitality research. Journal of Hospitality \& Tourism Research, 26, 199-216.

Fecikova, E. (2004). An index method for measurement of customer satisfaction. The TQM Magazine. 16(1), 57- 66.

Gronroos, C. (2000). Service management and marketing. John Wiley \& sons, Ltd, P. 46- 65.

Kano, N., Nobuhiku, S., Fumio, T., \& Shinichi, T. T. (1984). Attractive quality and must-be quality. Journal of the Japanese Society for Quality Control, 14(2), 39-48 (in Japanese).

Meng, J.G., Summey, J. H., Herndon, N.C., \& Kwong, K.K. (2009). Some retail service quality expectations of Chinese shoppers. International Journal of Market Research, 51(6), 773-796.

Mirghafori, H, Maki, F. (2007). Evaluation of quality of library services training by Libqual approach. Journal of Library and Information Science, 10(1), 62-79.

Parasuraman, A., Zeithamel, V. A., \& Berry, L. (1985). A conceptual model of service quality and its implication for future research. Journal of Marketing, 49(4), 41-50.

Parasuraman, A., Zeithamel, V. \& Berry, A. (1991). Understanding customer expectations of service. Sloan Management Review, 32(3), 39-49.

Frederick F. Reichheld and W. Earl Sasser, Jr. (1990). Zero defections quality comes to service. Harvard business review, 68(5), 105-111

Ueltschy, L. C., Laroche, M., Eggert, A., Bindl, U. (2007). Service quality and satisfaction: an international comparison of professional services perceptions. Journal of Services Marketing, 21(6), 410-423.

Wang, Y.G., Lo, H.P., \& Hui, Y.V. (2003). The Antecedents of Service Quality and Product Quality and their influences on their influences on Bank Reputation: Evidence from the banking in Chinas. Managing Service Quality, 13(1), 72-83. 